\title{
Transferring Qualities from Horseback Riding to Design
}

\author{
Kristina Höök \\ Mobile Life@ Stockholm University \\ Forum 100, 16440 Kista, Sweden \\ kiah@mobilelifecentre.org
}

\begin{abstract}
We see more and more attempts to design for bodily experiences with digital technology, but it is a notably challenging design task. What are the possible bodily experiences we may aim to design for, and how can we characterise them? By analysing a horseback riding experience, we came to identify the following themes: (1) how certain kinds of bodily experiences are best understood through experiencing them yourself - the bodily ways of knowing, (2) how rhythm and balance create for particularly strong physical experiences of this kind, (3) how movement and emotion coincide in these experiences, (4) how the movement between seeing our own bodies as objects vs experiencing in and through our bodies is one of the ways we come to learn the language of expressing and understanding bodily action, and (5) how this in turn lets us describe the sensitive and delicate relationship of wordless signs and signals that represent, in the case described, two bodily agents - a human and a horse. When the human-horse relationship is really successful, it can be described as rare moments of becoming a centaur. We translate these themes into design considerations for bodily interactions.
\end{abstract}

\section{Keywords}

Embodiment, experiential qualities, bodily interaction, autoethnography

\section{ACM Classification Keywords}

H.5.2 Information interfaces and presentation (e.g., HCI): Miscellaneous.

\section{INTRODUCTION}

Originally, HCI spun off from ergonomics through its focus on the cognitive aspects of interaction. With the turn to third-wave HCI with its focus on experiences [2], we are now in a sense turning back to the body in interaction. But contrary to the main focus of ergonomics, instead of documenting and altering routines, finding error-free ways of involving operators in the complex beast of man and machine as a unity, or measuring how the body has its limitations, this turn back to bodily interaction entails a new

\footnotetext{
Permission to make digital or hard copies of all or part of this work for personal or classroom use is granted without fee provided that copies are not made or distributed for profit or commercial advantage and that copies bear this notice and the full citation on the first page. To copy otherwise, or republish, to post on servers or to redistribute to lists, requires prior specific permission and/or a fee.

NordiCHI 2010, October 16-20, 2010, Reykjavik, Iceland.

Copyright 2010 ACM ISBN: 978-1-60558-934-3...\$5.00.
}

focus. The renewed HCI interest lies in designing for experiences - beyond efficiency and task completion [19]. In some respects the ergonomists were more sensitive of the body than we are.

As digital products have become an integral part of the fabric of everyday life, the pleasure they give, the contribution to our social identity, or their general aesthetics are core features of their design. We see more and more attempts to design for bodily experiences with digital technology, but it is a notably challenging design task. With the advent of new technologies, such as biosensors worn on your body, interactive clothes, or wearable computers such as mobiles equipped with accelerometers, a whole space of possibilities for body-based interaction is opened.

But this begs for answers to three questions. First, what kinds of experiences are we aiming to design for? Glossing them over as all being about designing for flow [3] or inducing a game play experience is too vague [8]. We need to drill deeper and better understand exactly what experiences we are talking about. Are we designing for pleasurable or unpleasurable ones? Are we designing for those that are subjective and unique, or ones that are common and shared? Ones that deliver serendipitous experiences or ones that are evocative and emotional? These are not all the same, even if all may emphasise aspects of bodily experience.

A particularly difficult issue lies in understanding how these experiences may unfold over time - both in the particular interaction with and manipulation of the artefact but also as parts of our everyday on-going lives. As Löwgren [17] puts it, a gestalt for interactive artefacts is defined as a dynamic gestalt which "we have to experience as a dynamic process" (p. 35 - 36).

Second, once we know what kind of experience we are aiming to design for, we need to describe them in a form that makes sense and that we can share within a design team. Ways of knowing can arise from your bodily acts without any language translation in-between. The feel of the muscle tensions, the touch of the skin, the tonicities of the body, balance, posture, rhythm of movement, the symbiotic relationship to objects in our environment - these come together into a unique holistic experience. It is not the ability to fulfil a task, but the experience of the corporeality of doing so that matters here. Those descriptions also need to be shared with the users that we invite to test our designs, or even participate in the design process. 
Thirdly, if we try to design interaction that builds on bodily movement, seeking certain experiential qualities, many different aspects of the interaction have to be fine-tuned to enable the experience, as, for example:

- the timing of interaction: movement has to render response in exactly the right moment for exactly the right kind of length of time in order to create for a particular experience [27]

- linking emotion and movement: certain movements and body postures are more likely to coincide with certain emotional experiences [4, 13, 25]

- harmony of modalities: the modalities of the interaction, such as graphics, haptics or gestures, all have to speak together - harmonize [26]

To shed some light on these issues, we decided to study a non-digital activity that is unambiguously about the body's involvement - a mundane activity to some of us - horseback riding. Also, as it happens, horseback riding is an activity the author has a passion for. There is a plenitude of activities that we do for the pleasure of moving - dancing, sports, jogging, cycling. The pleasures of these activities are of course not only soft, nice movements, since some of the activities involve pain, applying yourself really carefully to make your body do them, adjusting your own body in various ways, even making your body build certain muscles that you normally do not use so much, embarrassment when you do not get it right, and so on. But they are still rewarding. The pleasure of moving a muscle that is aching, or the adrenalin rush when you ride your horse and almost loose control, makes some of us feel that we are living life to its fullest - away from the safe office environment were the excitements (and there are of course plenty of them) will not, to the same extent, move your muscles, bones, joints and stimulate the nervous system of the whole body.

\section{STUDY SET-UP}

The study is done by the author, who is not a professional horseback-rider. Instead, we portray a mundane activity of someone doing her favourite leisure activity, an amateur. From here on, I will therefore use the pronoun 'I' when I speak about my subjective, personal experiences of riding.

The account is an autoethnography, that is a form of autobiographical personal narrative that explores the writer's experience of life. It has been used in the sociology of new media, journalism and communication studies. Autoethnography (though controversial) has recently started to be used in HCI [15], most notably by Boehner and colleagues who also use it as a design method [1].

The study was done through video taping and taking notes of seven riding lessons. The videotaping was done both by the riding instructor, Christian, and by cameras placed next to the paddock where the riding happened. The instructor also watched one of the videos and made comments to it that I used in the analysis. All of what was said in the videos was transcribed, and snippets of video were cut out and analysed in detail. I wrote down detailed accounts of the riding experience after each of the seven lessons. These notes were juxtapositioned with the written transcripts of the videos. I also discussed the material with two colleagues who helped me analyse the data. The accounts I provide below are sometimes quite detailed as I am trying to come to the essence of the riding experience.

At the time, I was re-learning how to ride in English style as I had been riding Icelandic style for many years. The Icelandic style of riding is quite different from English: the Icelandic horses are smaller, have more gaits (including tölt and pace), the saddle is placed further back on the Icelandic horse, the stirrups are kept longer, and the horses are trained to interpret the signs and signals the rider emits (from legs, hands, body posture) differently. The way to ride English style is to try to be relaxed and balanced, not disturbing the horse through squeezing your legs too tightly or pushing with your rear muscles. The aim is not to put any tension into the horse - while on Icelandic horses, it is necessary to put tension into the horse in order to enable (unusual) gaits such as tölt. The account given here is therefore the story of an instructional situation. Teaching and learning are at core.

\section{THE FELT EXPERIENCE OF RIDING}

There are many ways I could look at the data from this horseback-riding experience. I could look upon it mainly as a learning experience, analyzing each painful step of getting my body to behave in the English-riding style, and figuring out the ways by which my teacher Christian is trying to help me 'see' and correct my posture. This is similar to a study by Laurier and Brown, where they talk about Laurier's father teaching him to see the various phenomena involved in fly fishing [14]. I could describe the ergonomics of the interaction between me and the horse in terms of errors, task completion time or bodily muscle acts. Or I could analyze how the two agents (me and the horse) are communicating. I will attempt to give some accounts of all those situations, but I want to approach the difference between describing various moments in the interaction (from what can be seen e.g. in a video of my riding), to instead describing aspects of the feeling of my experience. Rather than glossing over that experience as flow or other experiential qualities, we would like to describe the unique experience of horseback riding with Christian and his horses, named Blue, Henry and Liberty in terms that hopefully preserve the essential elements of that experience. Here I do not want to suggest that there is a unique subjective experience that I want to describe, so much as preserve what the American philosopher Quine called the inscrutability of reference: the actual thing that is empirically existent, for any and all persons [22]. I would like to describe how we sometimes become part of each others' lived experience [5], how I experienced my own body, the horse's body and the rare moments when we were in synch and I became totally absorbed by the situation.

The following themes are extracted from the analysis of my experience. They have to do with the various orientations to 


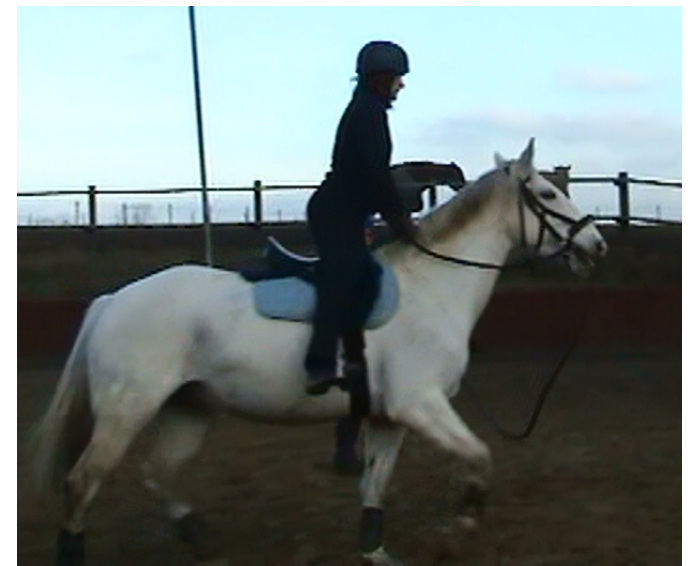

Figure 1 Standing in the trot to feel the weight in my heels, finally loosening my legs from Blue's body.

experience that are constituted in the domain of horse riding:

- how certain kinds of bodily experiences are best understood through experiencing them yourself - the bodily ways of knowing,

- how rhythm and balance create for a strong physical, aesthetic experience

- how movement and emotion may coincide in this particular instructional setting

- how I move between seeing my own body as an object vs. experiencing in and through my body is one of the ways we come to learn the language of expressing and understanding bodily action

- how this in turn lets us describe the sensitive and delicate relationship of wordless signs and signals that represent, in the case described, two bodily agents - a human and a horse

- $\quad$ rare moments of becoming a centaur - that is feeling as 'one' with the horse

\section{Bodily ways of knowing}

The interaction with a horse is obviously not word-based. It happens through physical signs and signals: the riders use the muscles in their legs, the placement of their sitting bones, bodily balance, head movement, hand and arm connection to the horse's mouth and sometimes tone of voice. The horse talks back through its movement, direction, pace, activations of muscles that can be felt throughout the horse's body, its head movements, tail movements, flipping ears, bend of neck and noises. In order to be a good rider, you need to learn this wordless language. As in any language, understanding and communication arises in interaction over time. When you have experienced a particular bodily schema or concept yourself this understanding may arise. Let us provide one example of such a process.

During the lessons, Christian kept saying that it was important that I put weight into my heels. This was where my balance was going to come from. As I had been squeezing my knees tightly to the horse's sides and pushing with my sitting bones into the saddle, I could not understand what he meant. I tried making my heel the lowest point of my body rather than my toes, but I was still not getting it. It became a contrived position for my body, my heels were forced down and as soon as I forgot about pushing them down, they crept up again.

Christian decided to help me understand where my weight should be through a special exercise. He asked me to stand up in the saddle, see Figure 1, at first while the horse was standing still, then while walking and finally while trotting. Standing in the saddle like this forced me to try and find my own balance without squeezing my legs to the sides of the horse whatsoever. Suddenly I realized what Christian had meant by putting weight into my heels. My whole weight had moved down to my heels and it was from there that I found my balance. I felt my own weight travelling down, gathering around my ankles, and the sole of my feet became like a floor. When I was allowed to sit down back into the saddle, I knew what the feeling should be - which muscles should be activated, what my ankles and feet should feel like and I experienced, inside my body, inside my balance, my own weight.

While I can rationalise what was needed afterwards and decompose exactly which body parts needs to be loose or tensed, it is not this decomposition that I learnt. I learnt a whole body schema, a wholeness that only made sense if I got all parts at the same time. This was a key element in the vocabulary of rider-horse relationships, how the sense of being a centaur is realisable.

This insight did not come from being told a visual metaphor (I had already been told, repeatedly, in various ways to put weight into my heals), or from Christian showing me through riding himself what it should look like. In my case, I had to experience it myself in order for it to be meaningful to me. This is not to say that it is impossible to be told how to move your body or simply imitate and thereby constructing meaning. The more experienced you are in listening to bodily instructions, as a rider, dancer or in other bodily activities, the better you will be in following the instructions and thereby experiencing the movement. But the knowing itself does not come from the description of movement - it comes from the experience of it. Or in this case, the concept "putting weight into your heels" did not make sense to me until I had experienced it - the meaning of the words was intrinsically tied to the action. Without the action they conveyed insufficient knowledge to let a person 'do' the action in question

\section{Out of rhythm and embarrassment}

As horse and rider move together, they create a rhythm. Depending on the gait, it can be a two-beat (trot, pace), three-beat (canter), or four-beat (walk, gallop, tölt), in different paces. To allow the horse to keep the beat in a balanced way, the rider needs to make herself invisible in the saddle, not disturbing the rhythm. 
In one of the earlier lessons, as I was repositioning my body from Icelandic style to English, I totally lost everything. In particular, I lost my ability to follow the rhythm of the horse. I was 'behind the movement' as Christian phrased it when commenting on the video of me riding:

"As you come into better balance the horse is more forwards. But then you lent forward and pulled on the reins so that he slowed down and fell in on the circle. There is still the tendency with the leg to go too far forwards so the seat of the rider is pushed to the back of the saddle and the shoulders come forwards so the rider is turned as what we would call 'behind the movement'. You are not in time with the horse but you are always trying to catch up with the horse. You can actually see that quite clearly there. He is trotting in one rhythm and the rider is in a slightly different rhythm."

The experience of being 'behind the movement' is very awkward. The trot is a 2-beat movement in which the horse's legs move in diagonally opposite pairs separated by a moment of suspension. In a rising trot, the rider needs to rise from the saddle in every second stride. You need to let the movement come from the horse moving you upwards. When it does, you continue the movement forwards, rather than straight up. In the next stride of the horse, you then come back down, and if you are in rhythm, you will come back into the saddle, briefly, at exactly the right beat, immediately going up again. Your whole body needs to listen to the rhythm of the horse, because unless you are in perfect synch with the horse, the horse's strides will not be perfectly even - your movement disturbs the horse.

The problem was that I was sitting back into the saddle with a 'splat' slightly out of rhythm with the horse. Given how many years I had been riding before going to lessons with Christian, it was horribly embarrassing for me to be out of synch. Following the rhythm of the horse is one of the most important pleasures of riding. As discussed by others [21] rhythmic movement as in dance or riding, moves us in way which are immediately appealing. But just as it can be very awkward to watch someone dancing out of rhythm, it is very awkward to experience it. Being out of rhythm on the horse, is especially awkward as it inflicts on the horse to have the weight of an adult human rider bouncing down into its back at the wrong moment, just as the horse is about to rise.

But my embarrassment did not arise only from knowing that Christian could see me and condemn my riding. Nor from my worry about how the horse had to deal with my weight bouncing into his back at the wrong moment, even if this also contributed to it. The embarrassment came from the actual physical experience of being out of rhythm. Our bodies are used to rhythms, our own bipedal swagger [25], our mother's heart beat, waves beating the beach, music and dancing, and, for those who are fortunate enough to experience it: the horses' different gaits.

This particular incident happened when I was still trying to get to terms with how much bigger the stride was with a big

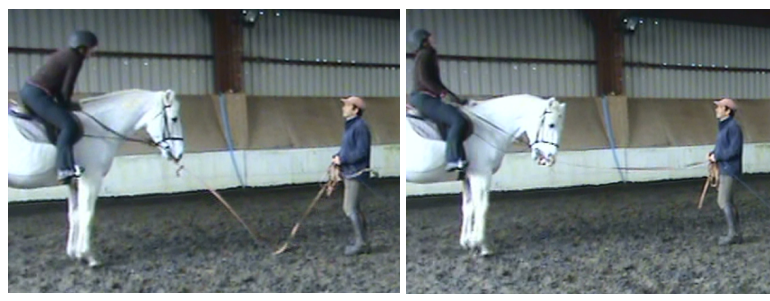

Figure 2 Feeling very embarrassed by how badly things are going. I make a stupid remark, lean forward as if to release tension, sit down again, and pull my shoulders up, face upwards, giggling awkwardly.

horse compared to the small Icelandic horses. The movement was more of a huge big ship moving up and down, rather than the fast up and down rising on Icelandic horses. I had to make my body listen to and get into this bigger rhythm. As I was trying to adjust my way of sitting, experimenting with where my weight was, loosening the grips of my knees, avoiding to flex my back too much, pushing my heals down, and avoiding to push my sitting bones into the saddle, the rhythm did not come 'naturally'. I did not have the ability nor prior experience of the feeling that would allow me to attune my body posture to how the horse responded, and make it respond the way I wanted.

Being inside a dynamically rapidly changing situation where you are simply not getting it right, it is very hard to make sense of what to prioritise, what to fix. When Christian stopped me, I was therefore totally devastated by the situation. I was out of synch with the horse and I had no hypotheses about what to do or what was actually wrong. I tried joking about it and made some embarrassed movements with my body, as you can see in Figure 2.

In a sense, this is similar to Ingold's description of plank sawing [9]. He nicely shows that no matter how experienced you are, sawing through yet another plank will never be exactly the same. There are number of different sensations that synchronise in a particular riding experience. Rapidly adjusting to each one of them, will in every new instance be a unique experience.

\section{Getting into the rhythm - being one with the horse}

Towards the end of the third lesson, after having been embarrassed, out of rhythm and very confused, I had, in a way, given up all my good intentions of putting my body in the right place and working hard to make it work. Instead, I allowed myself to be distracted by Christian who was talking about something irrelevant, I relaxed and then I finally got the rhythm of the horse. Suddenly, without consciously trying to, I shifted my weight further back in the saddle and suddenly it worked. I rose at the right moment, I was relaxed in the way I was sitting and the whole thing felt fleeting and nice.

At this point, as I was relaxing, just feeling the rhythm of the trot, I was not really thinking of where my different body parts are placed, nor was I thinking about the rhythm as such. I cannot say that any clearly formulated thoughts flew through my mind. Indeed, one could say that I am not 


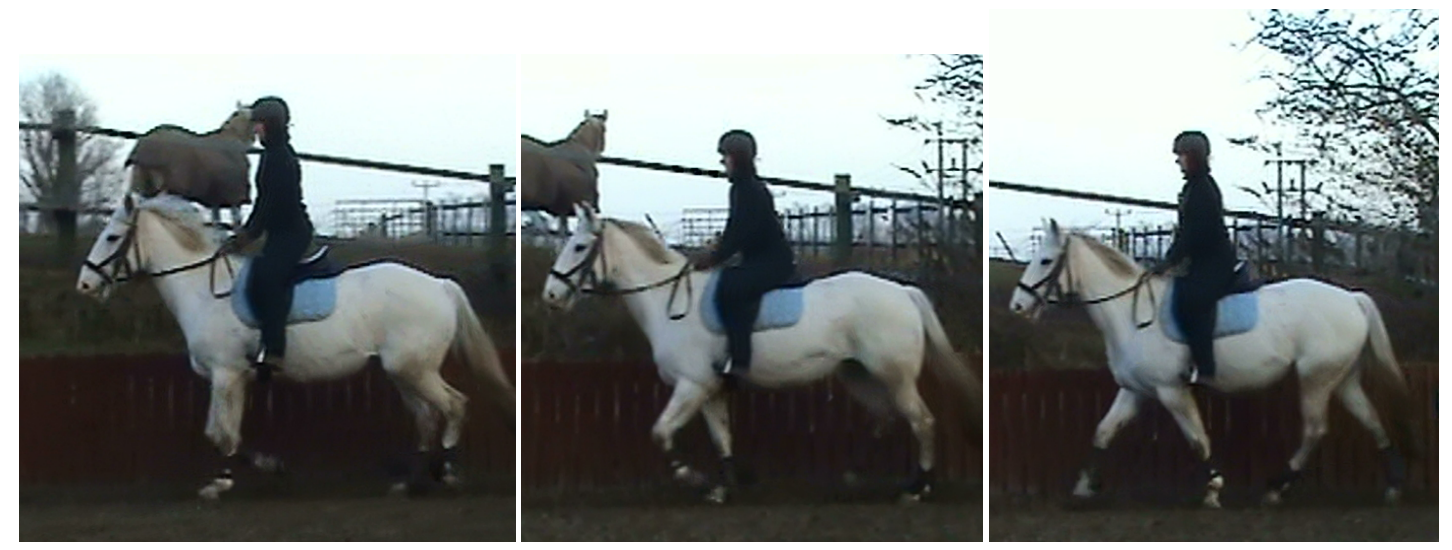

Figure 3 With my body in balance, more or less straight back, weight in my heals, in rhythm with the horse's trot, rising at the right moment, and overall relaxed.

thinking at all. Thinking is precisely not what is required, I was simply entirely absorbed by the situation. My muscles were doing what they should be doing, my eyes were directed towards where we should be going, my hearing followed the rhythm of the horse's hooves on the ground, and I felt as one with the horse. We were no longer separated but moved together with one intention, one will. My whole self was simple there, in synch with the movement.

In Figure 3, we can see that my body is not leaning forwards, my legs are not too much forward (though still not perfectly in line with shoulder and hip), and I am looking in the direction of where we are heading.

I asked Christian to comment on the video of me, and at this point, when I get into rhythm, he said:

"Much better rhythm. And again, the rider is better balanced the horse goes forwards more fleeting. He is more even in his rhythm. A lot of this you can see straight, anybody watching this can see the difference. There is much better. You can argue that yes ok you are still a little bit forwards and the rider is still a bit behind the movement. But overall it is much better."

He also confessed that he had used one of his strategies to get me into this state:

"Very often, especially with adult riders or nervous riders, if you stop them thinking too intensely about what they are trying to do then their body takes over their reflexes kick in and then people tend to ride in a more relaxed and better balanced way because they are not thinking too much about what they are doing, they are just doing it and that is better. So sometimes you just chat about going to the hairdresser or something."

When Alan Kay talked about how he worked through the ideas of the desktop metaphor and the use of the mouse for drag-and-drop, point-and-click, he picked up on the same insight [10]. He had been inspired by a TV-show of how a tennis teacher was able to distract his pupils by making them sing songs while learning to do backhands, forehands and serve. Through these distractions, the pupils were distracted and their bodies simply imitated the right physical movements without giving it much thought.

\section{Seeing my body as an object vs experiencing in and through it}

When learning bodily practices such as tennis, golf or skateboarding [29], you occasionally will have to change your posture or aspects of your movements in order to correct some aspect of your performance. These changes can be very painful as they feel unnatural - the prior, faulty, behaviour keeps interfering. Those situations require that you consciously reflect upon different body parts, where they are, what they feel like in that position and how to move them into the new, required position or tension level.
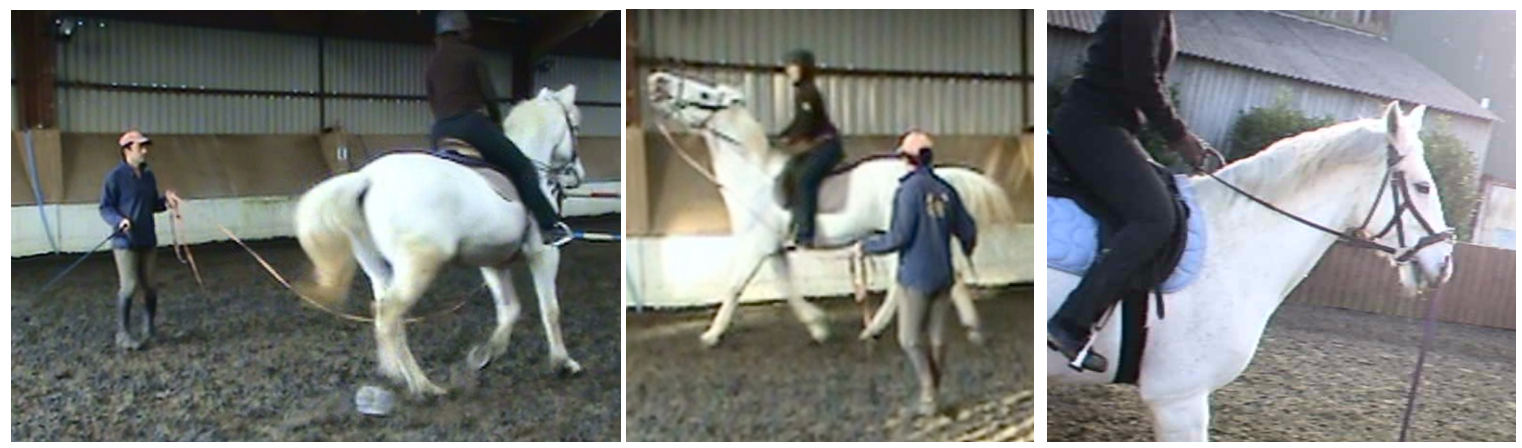

Figure 4 My leg actively lifted away from the Henry's side, without putting any weight into the heel, leaving me unbalanced (left). Leaning far too much forwards (middle) annoying Henry. Not putting any weight into my heel on Blue (right). 
Christian, talked me through one of these re-positionings of my posture:

"Sit in the centre of the saddle, balance squarely on both seat bones, your back should be straight, your legs should relax along the horse's sides, and the idea is that there is a straight line from your shoulder, through your hip to your heal. Your arms should fall softly by your sides. There should be a straight line running from your shoulder, through your elbow, through your wrist and down the rein to the horse's mouth. There should be a 'spring' between your heal knee and thigh that makes it possible to do a rising trot. You should put your weight in your heels and not lean your body forwards but be straight."

You may note how each body part has to be in the right position and how each muscle needs to be activated or relaxed exactly in the right way. In this description, there is an emphasis on being soft, relaxed and balanced. Christian kept emphasising that I should keep my own balance, that I should not disturb the horse. Christian used some visual metaphors to describe what it should feel like, such as "the horse should be flowing like a river through the reins, your arms, and between your legs".

As I had been riding in the Icelandic style for most of my adult life, the re-learning of how to sit proved to be very hard. The problem for me was that as soon as I tried to do something with the horse like steering it or asking it to move somewhere, rather than just thinking hard about how I sat or where my different limbs where, I immediately fell back into squeezing my knees tight to the horses sides, pushing my legs to be straighter and more forwards, and pushing my butt hard down into the saddle. My whole body was screaming that Christian's way of sitting was not the way I was used sitting and I comfortably moved into the position my body 'knew' best.

When re-learning how to position my body, my body become an 'object' that I controlled with my will. Or rather, what has hitherto become a matter of habit, a way of the body that one takes for granted, now becomes something that I focused on. My mind starts to think again, about how the body should be.

During my third lesson riding with Christian, he had decided that he was going to change my way of sitting and thereby influencing the horse. He did so by lounging the horse around him so that I could focus entirely on how I was sitting without having to steer the horse or control it. Halfway into the lecture, I was still sitting all wrong. Since Christian had asked me to relax my legs and last time he had complained about my knees squeezing, I was now letting them hang down totally free from the horse's sides even actively lifting them away from the horse's sides, see Figure 4. To overcome my difficulties Christian had to find a way to show me what the problem was. Describing it through the visual metaphors he used had not helped. In the seven lessons I took with Christian, he used a range of ways of showing me: he showed with his own body what my body was looking like when I was in the wrong posi- tion, see Figure 6, he touched or pointed to parts of my body that needed to relax or be more tensed, he rode the horse himself so that I could watch his body and imitate, and he made me do some 'extreme' exercises to provide me with a bodily experience (as described above when standing in the stirrups), or as he phrased it, helping me to create "a muscle memory" of where he wanted certain parts of my body to be placed or what it should feel like.

Through these exercises, Christian occasionally helped me to get into a position where I was balanced, experiencing the kind of interaction between me and the horse that he wished to see. Being in synch with the horse, following its rhythm, and being perfectly balanced myself, happened rarely. But at those moments when I went from actively thinking about where a certain body part was placed, to actually feeling that "this is a good position", I also typically would switch from seeing that body part as an object from the 'outside', to instead being 'inside' my body, feeling the interaction from inside my body. In Figure 5, we can see one such moment. Again, my body is not leaning forwards, my legs and knees are relaxed, and my head is turned in the direction of where we are going. The horse also has a nice forward movement. It gave a sense of relaxed concentration - I am totally inside the experience, but in a relaxed way.

Learning a movement, a posture, a rhythm, as was required of me here, is to try learn a habit or as phrased by Game [5], "the movement of music, riding, writing, lives in us as we live in it."

\section{Being In the World Together}

When things go really well, I feel the presence of the horse's way of being in the world as part of my own and we act together. This sense of another agent being present relies on a process of recognition. The horse and my self become one, as the centaur mentioned above. But sometimes - indeed in my case quite often as I struggled with learning to ride in a new way with horses unfamiliar to me - my orientation to other, the animal in this case, evokes the idea of the mind and how it is somehow separate from the body. To be able to merge with a horse, one has to get the feeling that the horse's mind and its body are as one, and the mind is not being mischievous in a way that leads the body to convey misleading signals.

This sense of another mind being present relies on what Jane Heal describes as an empirical exercise of the imagination [6]. I recognize the individual horse, how I imagine it is thinking, it's personality and I 'talk' to it. Through this operation, I come to see that it is not alien to me at all, but an individual that I emphatically recognise through its horselike way of thinking and being in the world and how it is trying to listen to me.

The problem with Christian's horses is that I did not know them as I was a newcomer to his stables - my ability to construct in my mind's eye, a sense of them, of their personality, of their mind, could not work. The ultimate test of this failure: I did not recognise what they were thinking. 

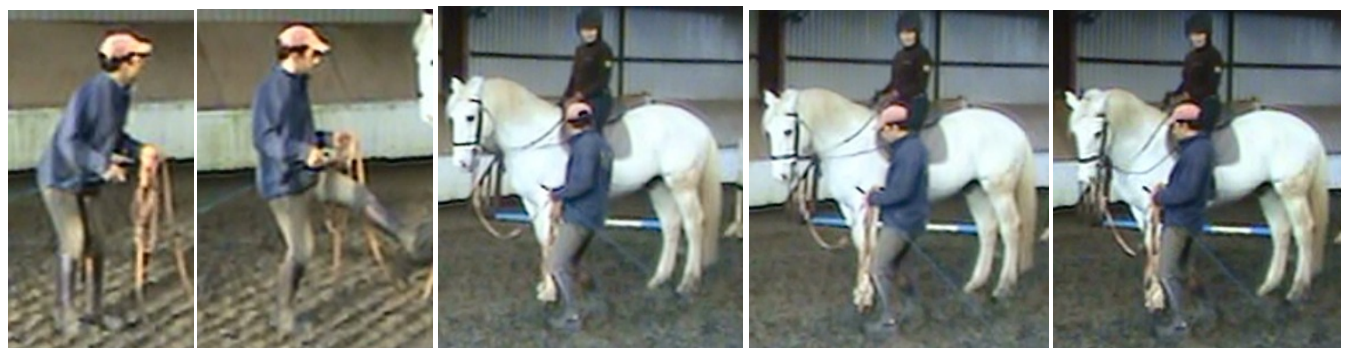

Figure 6 Christian showing how my butt is sticking out and my legs are pointing forwards (two leftmost pictures). Then showing what my body position should be, and how I can be rising from the position (three rightmost pictures).

Their stride was much bigger than the Icelandic horse and it made me feel that maybe this is a different kind of animal. Not a horse as I know them but some other kind of intelligence. These horses do in fact have quite different behaviours compared to Icelandic horses as they are more nervous, higher strung (a quality that breeding has emphasised as these horses were used in war and therefore bred to be very fast and have quick reactions).

Christian's way of teaching and my focus on the way I was sitting did not give me much room to establish this kind of relationship or explore who the horse was. His horses were also very well behaved, allowing me to concentrate on my way of sitting rather than controlling the horse. An exception was perhaps the horse named Liberty. Liberty was a huge, big horse that kept chewing on everything in a playful style, mirroring a teenager. Not dangerous, but a bit nervous and silly. The kind of horse who like to pretend to be spooked by some dangerous shadow in a corner, allowing it to get away with jumping here and there in a way that makes riders like me totally distraught and immensely nervous.

At the beginning of the lesson with Liberty I was immensely tensed. Liberty has already on our way towards the riding track decided that there were ghosts everywhere and was 'spooked'. I could feel his tension and how it increased by my tensed movements. My butt-muscles and armmuscles were extremely tensed. I tried to make them relax, but failed. The tension in my arms made them straight and stiff rather than bent at the elbow and relaxed along the sides of my body. Christian could see how tensed I was and asked me to stop being so silly.

During the lesson, I felt that Liberty was not listening. My feeling was that I needed to take more control, provide more signs to make him listen to me and start collaborating. I did not feel that Liberty was testing me, more like he was genuinely into his own thing, being spooked, and not that interested in me. I therefore tried to distract him, make him listen to me. I pulled at the reins to say "hello, I am here listen to me". I shifted in my seat, and I made my legs 'present' in the interaction. But it felt as the more I tried to get in contact, the more he closed off and did not want to listen. He just became more silly, more easily spooked. I did not feel that I was in control of the horse, something that makes any rider very nervous. As I did not feel that I could decide what to do on the riding track (Christian is in charge of what we do after all), I could not use the tricks that I would have liked to use - going into smaller volts, changing direction, distracting Liberty and getting his attention through saying "here I am, I want to do these things, let us have fun together".

As I was doing all of this 'give me attention'-business, I fell back into a bad habit of watching Liberty's head. By doing so, you can get some more signs of where the horse is heading, what it is thinking or looking at, and whether it is listening to you. But the rider should not be watching the horse's head. My head should be directed towards where we are going, since the balance of my head and the position of my shoulders tell the horse where we are heading. I also need to plan ahead where we should be going next, preparing the horse and myself for what is going to happen. If I look in the direction of where we are going, I will still see the horse's head in the periphery. And by looking at where we are going and planning our route, I stay in control, rather than acknowledging and giving the horse the control. On and off, I tried to stop watching Liberty's head, but because of this lack of contact or dialogue between us, I kept looking back at his head to be prepared for any action he would take. We were not 'one', but two that were not collaborating.

Towards the end of the lesson we finally connected. I was asked to canter, and for some reason, this made a lot of my tensions go away. I took more control in the canter, was not

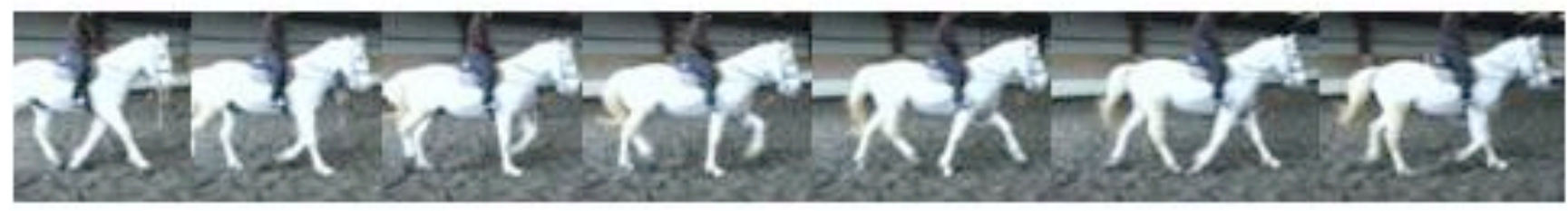

Figure 5 Finally, I am in the right position, balanced, and Henry is "flowing freely" with a forward gait (more or less). 
worried that he would start being spooked. As the speed increased, some of the nervous energy was let loose, and the steering was easier. The speed and the rhythmic beat of the canter are exhilarating in themselves - it became physically enjoyable. In particular, I felt that the canter helped me to get into rhythm and after each canter both Liberty and I were more loose, relaxed, flowing in our joint stride. Liberty's canter was big in its stride. It had a nice big, rolling rhythm. Together we went from canter to rising trot on and off. Both felt really good and relaxed. Liberty became more interested in the dialogue. The experience of it was fun, which in turn made the whole thing work. I only had to think 'forwards' or 'let's canter' and it happened.

To make this happen, true sympathy is required [5]. You have to recognise the otherness and difference in the horse and create a lived experience together. You have to forget about your own human self and instead turn yourself into a centaur self - consisting of two agents acting together. It is not without risks or wilderness, you might fall, the horse might take off in an unexpected direction. But when the connection and collaboration between the two minds happen, we both enjoy it.

\section{TRANSFERRING LESSONS LEARNT TO DESIGN}

In my view, there is no need to replace the horseback riding experience with a digital riding experience. This is not why I wanted to describe this experience. Instead, I want to transfer some of the qualities in the human-horse interaction into other applications we might want to create with digital technology - what Ljungblad and Holmquist name transfer scenarios [16]. Their idea is that we can learn from people's specific practices and use the qualities of those practices and transferring them into innovative design that can attract a more general audience. They have tested this process on e.g. studying reptile owners and transferring qualities of their relationships with their animals to the design of home robots. The difficult step in their method is narrowing down on (1) what the qualities are, and (2) which are worth transferring and (3) how to implement those in an innovative design. Here, I want to suggest what some of the more important qualities from my horseback riding experience that we may want to transfer to design.

I also want to point out that while others have also considered the importance of the body in design, e.g. [7, 12], their focus is most often on how to improve a function or serve a another purpose in the interaction, not on the aesthetics and enjoyment as an end-goal in itself (with some notable exceptions $[21,27,30])$.

\section{A sensitive and delicate relationship of wordless signs and signals}

The relationship between the horse and myself is based on non-verbal, very subtle signs and signals - a language of sorts even if not lexographical. There is a mutual space of signs and signals that we are involved in - to some extent translated by Christian, the instructor - but to a large extent happening between the two of us. This language worked to bring us together even though I assume that we are two agents with quite different ways of being in the world - my own human body's perceptual way of being in the world, vs. the horse body's perceptual being in the world. I learn to express with the horse so that I, as a rider, can come to emphatically understand how the horse lives in its world our world in common. When I do, and when I manage to capture the horse's interest and attention, we sometimes get into an experience where there is only one being, one center of experience, a centaur, an animal of two in a world made the same for both: for the horse and for me.

But when this is achieved, the two do not entirely merge. Important in horse-back riding is to leave space for the horse do its job - there is this space that I need to open for the horse to prefer to go there. I need to be out of the way, balanced in my own body, to not disturb the horse and its movement. As a rider, I found it very interesting to hear Christian's account of how he could see when I was sitting wrongly or inflicting in a bad way on the horse:

"I watch the horse. The horse tells me what the rider is doing. The shape of the horse. The dynamic confirmation. The shape of how the horse is moving. We saw that earlier on this video clip earlier when you were out of balance and the horse was going very short in his stride and he was coming into the middle of the circle all the time. And then when you became better balanced he opened his stride and went into the bigger circle."

This could be a quality of design that we might find interesting to transfer to some kinds of human machine interactions - such as robot-interaction or interaction with various intelligent systems in our environment. Rather than making that relationship an explicit language, it could build on bodily signs and signals, allowing robot and machine to create a mutual understanding (cf. the work by Sengers [24] and discussions on machine intelligence by Taylor [28]).

\section{Bodily Learning}

Many of the lessons learnt above where about bodily training. I found learning processes that to a large extent are already known from the literature on learning:

- If you distract the conscious self, you can make people use their 'muscle memory' or imitate and thereby get it right [10]

- That you can get into an all-absorbing state as I did towards the end of the lesson - which is similar to flow, being in the zone in sports, and a range of similar descriptions

- That we move back and forth between states where we can think about body parts and where they are placed or what they are doing as objects or instruments (present at hand) and states where we are inside the experience doing the thing (ready to hand)

But when we design interactional systems involving our bodies, we rarely discuss how this bodily learning process is supposed to happen. Intuitively, many designers build these kinds of processes into their systems, but there is no systematic description of how to do it. In a sense, HCI- 
research has been very concerned with zero-learning time. But as we could see from my account of riding, a great deal of the pleasure comes from applying yourself really hard, learning the movements that are needed in order to get to states of aesthetically appealing rhythmic interaction.

\section{Rhythm - an aesthetic experience}

I have kept coming back to rhythm, as it is an important aspect of riding. At the same time, it is an interaction quality we rarely talk about in our design processes even if we know that any interaction, be it bodily or a more traditional desk-top system, reveals its dynamic gestalt over time and space [17]. Any such interaction will have its rhythm - its ebbs and flows, intense or more slow reflective parts. But in the horseback riding, rhythm is a more intense experience, strongly intertwined with all the different parts of the riding activity.

Many of our everyday bodily experiences that we may want to mirror in interface design for sports, life style and heath applications will be rhythmically oriented. They may follow our circadian rhythm (biological processes following our 24-hour day), heartbeat, movement-oriented rhythm (picking up on walking or running behaviours), or everyday events (sleep, work, lunch, work, home). In my group, we have designed one such system named Affective Health $[18,23]$. It picks up on bio signals from sensors placed on the body, transmits them in real-time via Bluetooth to your mobile phone were they are portrayed as an animated, pulsating torus. Similarly, the artist George Khut has created a range of art installations where visitors can see their bodily states mirrored in captivating, colourful animations [11]. These are just a couple of examples of interactions where our own bodily rhythm makes the interaction come alive obviously we could imagine many more. Especially interesting are rhythmic interactions where the technology has some agency, moving us rather than us moving it.

\section{Describing Movement Experiences}

Above, I tried to provide an account of exactly how I was sitting, which muscles were tensed, how I balanced on my sitting bones, the direction of my head and vision, the position of my legs and the tension in arms and hands. Still, the experiences I am trying to describe are wordless, and putting detailed descriptions of them still fails to cover the complexities and the uniqueness of my embodied experience. We rarely describe bodily, experience-oriented, system interactions in such a detailed way (in $\mathrm{CSCW}$, there are system interaction descriptions based on conversation analysis, but their focus is mostly on the functionality, not on the subjective experience.) But in order to design for such interactions, we will have to do so. In particular, we need to start considering the aesthetics of movements. Why, for example, certain rhythmic movements feel awkward, and other states makes us leave our analytical selves behind, and instead allows us to be all-absorbed by the experience.

Through my description of riding I want to show how those bodily postures corresponded to my experience of being in those lessons with Christian. That experience was a mixture of my bodily posture, my expectations on my own expertise and embarrassment of having to relearn so much, my interaction with the horse, with Christian, and with the physical location - my embodied, lived experience. When MerleauPonty writes about the body he begins by stating that the body is not an object [20]. It is instead the condition and context through which I am in the world. Our bodily experiences are integral to how we come to interpret and thus make sense of the world. Our experience of the world depends on our human bodies, not only in a strict physical, biological way, through our experiential body, but also through our cultural bodies. Merleau-Ponty [20] attempts to get away from the perspective of the doctrine that treats:

"perception as a simple result of the action of external things on our body as well as against those which insist on the autonomy of consciousness. These philosophies commonly forget - in favour of a pure exteriority or of a pure interiority - the insertion of the mind in corporeality, the ambiguous relation without body, and correlatively, with perceived things". (p. 3-4)

Through integrated descriptions of both our experiential and cultural bodies, living everyday, mundane, practices such as horseback riding, we may be able to reach a body of work that we can use in the design processes. Similar to any artists, as designers we have to practice our sensitivities in seeing, feeling, doing, hearing bodily experiences.

\section{SUMMARY}

From a detailed account of my horseback riding, I have extracted a number of experience-oriented qualities. I have hinted at how those might be considered in design processes, such as:

- Designing spaces for mutual wordless understanding between human and machine

- $\quad$ Letting bodily learning take time and be a pleasure in itself

- Putting more emphasis on the aesthetic pleasures of rhythm when designing for bodily interaction

- Finding ways of describing experiences of bodily interactions that can serve as inspiration to design

Hopefully these kinds of insights can take us beyond designing for the experiences of the body to the narrow domain of games and entertainment. In my view, we need to return to being more concerned about our bodily experiences, returning to the care that ergonomics shows the body, but with a stronger focus on experience, and not only function.

\section{Acknowledgments}

This study was done while I was a visiting researcher at Microsoft Research in Cambridge, U.K. I would like to thank Richard Harper and Alex Taylor for comments on this study and their help in the analysis of the data.

\section{REFERENCES}

1. Boehner, K., Sengers, P. and Warner, S. (2008). Interfaces with the ineffable: Meeting aesthetic experience 
on its own terms. In ACM Transactions on ComputerHuman Interaction, 15 (3).

2. Bødker, S. (2006) When second wave HCI meets third wave challenges. Keynote paper, Proc. of NordiCHI.

3. Csikszentmihalyi, M. (1990). Flow: The Psychology of Optimal Experience. Harper Perennial, London.

4. Darwin, C. (1872/1998) The expression of emotions in man and animals, Third ed. by Paul Ekman. Oxford University Press, 1872/1998.

5. Game, A. (2001) Riding: Embodying the Centaur, 7 (4): 1, Body \& Society, 2001; 7; 1.

6. Heal J. (1989). Fact and Meaning: Quine and Wittgenstein on Philosophy of Language, Blackwell, Oxford.

7. Hillerup Fogtmann, M., Fritsch, J., Kortbek, K. J. (2008). Kinesthetic interaction - revealing the bodily potential in interaction design, Proc. of the 20th Australasian Conf. on Computer-Human Interaction: Designing for Habitus and Habitat, 2008, Australia.

8. Isbister, K. Höök, K. (2009). On being supple: in search of rigor without rigidity in meeting new design and evaluation challenges for HCI practitioners, In 27th international conf. on Human factors in computing systems, Boston, MA, ACM Press.

9. Ingolds, T. (2006). Walking the plank: meditations on a process of skill, in J. R. Dakers (ed), Defining technological literacy: towards an epistemological framework New York: Palgrave Macmillan, 2006), pp 65-80.

10. Kay, A. (2003). Education in the digital age. (27:45) http://video.google.com/videoplay?docid=2950949730059754521\&hl=en.

11. Khut, G. (2006) Interactive Art as Embodied Enquiry: Working with audience experience. In Edmonds, E., Muller, L., \& Turnbull. D. (Eds.) Engage: Interaction, Arts \& Audience Experience. University of Technology, Sydney, Creativity and Cognition Studios Press.

12.Klemmer, S., Hartmann, B., Takayama, L. (2006). How bodies matter: five themes for interaction design, In Proc. of DIS 2006: ACM Conf. on the Design of Interactive Systems. State College, PA, 2006.

13.Laban, R., Lawrence, F.C., (1974). Effort Economy of Human Effort, Second ed. Macdonald \& Evans Ltd., London, UK.

14.Laurier, E. and Brown, B. (2004) Cultures of seeing: pedagogies of the riverbank, Manuscript, Institute of Geography, Edinburgh Univ., 2004 online: www.geos.ed.ac.uk/homes/elaurier/texts/Laurier cultur es of seeing.pdf

15.Ljungblad, Sara (2009) Passive photography from a creative perspective: "If I would just shoot the same thing for seven days, it's like...What's the point?". Proc. of 27th International Conf. on Human Factors in Computing Systems, Boston, MA, USA, ACM Press.
16. Ljungblad, S. Holmquist, L-E. (2007) Transfer scenarios: grounding innovation with marginal practices, Proc. of the SIGCHI conf. on Human factors in computing systems, San Jose, California, ACM Press.

17. Löwgren J. (2001). From HCI to Interaction Design. In Chen, Qiyang (ed.), Human-Computer Interaction: Issues and Challenges, Hershey, USA: Idea Group Inc.

18. Kosmack Vaara, E., Höök, K., Tholander, J. (2009) Mirroring bodily experiences over time, Proc. of the 27 th international conf. extended abstracts on Human factors in computing systems, Boston, MA, ACM Press.

19. McCarthy, A. Wright, P. (2004) Technology as Experience. Cambridge, MA: The MIT Press.

20. Merleau-Ponty, M. (1962). The Phenomenology of Perception, C. Smith, trans., London: Routledge \& Kegan.

21. Moen, J., (2006). KinAesthetic movement interaction: designing for the pleasure of motion. Doctoral Thesis, KTH, NADA, Stockholm, Sweden.

22. Quine, W.V. (1960). Word and Object, MIT Cambridge.

23. Sanches, P., Höök, K., Kosmack Vaara, E., Weymann, C., Bylund, M., Sjölinder, M. (2010). Mind the Body! Designing a Mobile Stress Management Application Encouraging Personal Reflection, In Designing Interactive Systems, DIS 2010, ACM Press.

24. Sengers, P. (1998). Anti-Boxology: Agent Design in Cultural Context. Ph.D. Thesis, School of CS, Carnegie Mellon University. Technical Report CMU-CS-98-151.

25. Sheets-Johnstone, M. (1999) Emotion and Movement: A beginning Empirical-Phenomenological Analysis of Their Relationship, Journal of Consciousness Studies, 6, No. 11-12, pp. 259-277.

26. Ståhl, A., (2006). Designing for emotional expressivity. Unpublished Licentiate Thesis in Design, Umeå Design Institute, Umeå University, Sweden.

27. Sundström, P., Ståhl, A., and Höök, K. (2005). eMoto Affectively Involving both Body and Mind, In Extended abstract CHI2005, Portland, Oregon.

28. Taylor, A. S. (2009). Machine intelligence, Proc. of the 27 th international conf. on Human factors in computing systems, Boston, MA, ACM Press.

29. Tholander, J., Johansson, C. (2010). Bodies, boards, clubs and bugs: A study of bodily engaging artefacts. In Extended Abstracts 28th ACM Conf. on Human Factors in Computing Systems, Atlanta, ACM Press.

30. Tweneboda Larssen, A., Robertson, T., Edwards, J. (2007). The feel dimension of technology interaction: exploring tangibles through movement and touch, Proc. of the $1^{\text {st }}$ Intern. Conf. on Tangible and Embedded Interaction, ACM Press. 
